\title{
How A PID Controlling A Nonlinear Plant
}

\author{
Timbang Pangaribuan ${ }^{1, *}$, Sahat Parulian Siahaan ${ }^{1}$, and Shyh Leh Chen ${ }^{2}$
}

${ }^{1}$ Department of Electrical Engineering, Faculty of Engineering, HKBP Nommensen University, Jl. Sutomo No. 4-A, Medan 20234, North Sumatera, Indonesia

${ }^{2}$ Mechatronic Department, National Chung Cheng University, Daxue Road, Minxiong Township, Chiayi, 62102 Taiwan

\begin{abstract}
This paper investigates the weakness of feedback controller to find the best parameter of PID controller of a nonlinear inverted pendulum system (NL-IPS). Stability and performance analysis of a NL-IPS are carried out with combination of feedback and PID controllers. It is found that the NL-IPS which was stabilized by feedback controller provides some weakness. By addition of PID controller on closed loop NL-IPS will provide better tracking and response on zero steady state error.
\end{abstract}

Keywords: Feedback controller, nonlinear inverted pendulum, PID controller, steady-state error, weakness

\section{Introduction}

One of output of a nonlinear inverted pendulum model is angle movement, as shown in Figure 1 [1]. These dynamics [2,3] can be elaborated by nonlinear second order differential equation shown with its arrangement as can be seen in Equation (1).

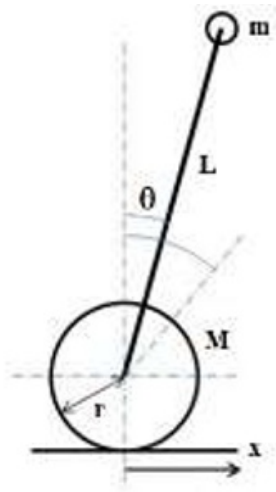

Fig. 1. Model of inverted pendulum.

$$
\left[\begin{array}{c}
\dot{x}_{1} \\
\dot{x}_{2}
\end{array}\right]=\left[\begin{array}{c}
x_{2} \\
\frac{g \sin \left(x_{1}\right)-a m L x_{2}^{2} \sin \left(x_{1}\right) \cos \left(\left(x_{1}\right)-a \cos \left(x_{1}\right) u\right.}{\frac{4}{3} L-a m L\left(\cos \left(x_{1}\right)\right)^{2}}
\end{array}\right]
$$

\footnotetext{
*Corresponding author: timbang.pangaribuan@uhn.ac.id
} 
Where $x_{1}$ is the angle of the pendulum (in radians) from vertical axis, and $u$ is the force applied to the cart (in Newtons). The various parameters and values are, $m=$ pendulum mass $=2 \mathrm{~kg}, M=$ cart mass $=8 \mathrm{~kg}, L=$ pendulum length $=1 \mathrm{~m}, g=9.81 \mathrm{~m} \mathrm{~s}^{-2}$, initial angle is $\theta_{0}=\frac{\pi}{6}$ and the other parameter can be seen at Equation (2).

$$
a=\frac{1}{m+M}
$$

For the class of nonlinear control system, the performance of the systems could be determined by eigenstructure of the closed loop system, if its state equation has approached and found in linear form. It is empirically true that the performance of a nonlinear system is determined by the eigenstructure of the linearized system around certain nominal condition. In this paper, a problem solving method for a nonlinear inverted pendulum plant is displayed, which is to design a single nonlinear feedback control law in such a way combined with proportional-integral-derivative so that a nonlinear closed loop system has a stable balance system. Clearly, this goal is motivated by intuition that the resulting closed loop nonlinear system performance is sensitive to variations in initial values that can be changed at any time.

By using the local stability analysis of fixed points in two-dimensional nonlinear ordinary differential equations such as Equation (1), it is based on approximating the nonlinear equation with linear equation $[4,5]$ in the following below, as Equation (3):

$$
\frac{d x_{1}}{d t}=f_{1}\left(x_{1}, x_{2}, u\right), \frac{d x_{2}}{d t}=f_{2}\left(x_{1}, x_{2}, u\right)
$$

The liniearized parameters at the initial conditions $x_{1}(0)$ is found with the Equation (4) below:

$$
\begin{aligned}
& a_{11}=\frac{d f_{1}\left(x_{1}, x_{2}, u\right)}{d x_{1}}, a_{12}=\frac{d f_{1}\left(x_{1}, x_{2}, u\right)}{d x_{2}}, b_{1}=\frac{d f_{1}\left(x_{1}, x_{2}, u\right)}{d u} \\
& a_{21}=\frac{d f_{2}\left(x_{1}, x_{2}, u\right)}{d x_{1}}, a_{22}=\frac{d f_{2}\left(x_{1}, x_{2}, u\right)}{d x_{2}}, b_{2}=\frac{d f_{2}\left(x_{1}, x_{2}, u\right)}{d u}
\end{aligned}
$$

By using Equation (3) and Equation (4), the linearized of Equation (1) can be solved as Equation (5) below:

$$
\left[\begin{array}{l}
\dot{x}_{1} \\
\dot{x}_{2}
\end{array}\right]=\left[\begin{array}{ll}
a_{11} & a_{12} \\
a_{21} & a_{22}
\end{array}\right]-\left[\begin{array}{l}
b_{1} \\
b_{2}
\end{array}\right]
$$

It was found that the linearized system was found as Equation (6) below:

$$
\begin{gathered}
{\left[\begin{array}{l}
\dot{x}_{1} \\
\dot{x}_{2}
\end{array}\right]=\left[\begin{array}{cc}
\frac{g \cos \left(x_{1}\right)\left(\frac{4}{3} L-a m L\left(\cos \left(x_{1}\right)\right)^{2}\right)+2 a m L g \sin ^{2}\left(x_{1}\right) \cos \left(\left(x_{1}\right)\right.}{\left[\frac{4}{3} L-a m L \cos ^{2}\left(x_{1}\right)\right]^{2}} & 0
\end{array}\right]} \\
-\left[\frac{a \cos \left(x_{1}\right)}{\left[\frac{4}{3} L-a m L\left(\cos \left(x_{1}\right)\right)^{2}\right.}\right]
\end{gathered}
$$

By using the plant's parameters above, with $x_{1}(0)=\theta_{0}$, the state Equation (4) can be found at Equation (7) below:

$$
\left[\begin{array}{l}
\dot{x}_{1} \\
\dot{x}_{2}
\end{array}\right]=\left[\begin{array}{cc}
0 & 1 \\
11.8333 & 0
\end{array}\right]-\left[\begin{array}{c}
0 \\
0.0732
\end{array}\right]
$$




\section{Method of design}

The first step to determine the stable plant, the optimal control [5] was defined at Equation (8) below:

$$
A^{T} P+P A-P B R^{-1} B^{T} P+Q=0
$$

Equation (8) only can be solved if the control law has Equation (9) below:

$$
K=R^{-1} B^{T} P
$$

Where $A$ and $B$ are parameters of plant from Equation (6) or Equation (7), $P$ is the definitive symmetry matrix, $Q$ is the optimal weight and $K$ is the optimal feedback. By using the MATLAB to solve the Equation (7), it was found that the optimal system give the Equation (10) below:

$$
\left[\begin{array}{l}
\dot{x}_{1} \\
\dot{x}_{2}
\end{array}\right]=\left[\begin{array}{cc}
0 & 1 \\
-49 & -7
\end{array}\right]-\left[\begin{array}{cc}
0 \\
0.042
\end{array}\right]
$$

The response of optimal plant was found as shown in Figure 2. The response was good, but the amplitude of the response was too low.

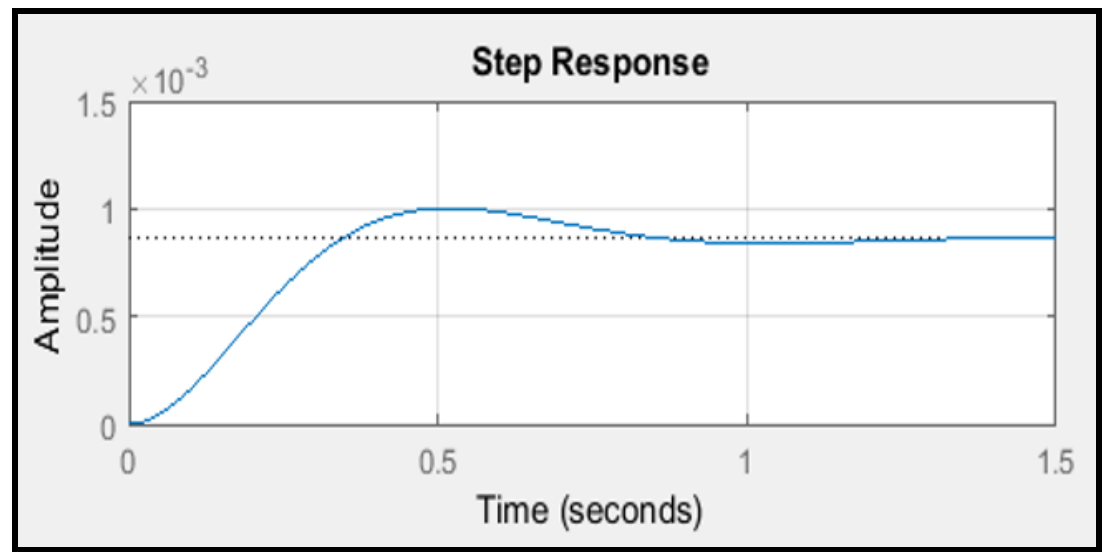

Fig. 2. The optimal response of inverted pendulum.

The second step to determine PID also in the optimal control [6, 7] was defined in Equation (11) below:

$$
u(t)=K_{P}+\frac{K_{I}}{s}+K_{D} s=\frac{K_{P} s+K_{I}+K_{D} s^{2}}{s}
$$

The transfer function of Equation (10) can be defined in Equation (12) below:

$$
G(s)=\frac{b}{s^{2}+a_{1} s+a_{0}}
$$

In the form of closed loop system using PID as a controller, Equation (11) and Equation (12) give the Equation (13) below:

$$
G(s)=\frac{b\left(K_{D} s^{2}+K_{P} s+K_{I}\right)}{s^{3}+\left(a_{1}+b K_{D}\right) s^{2}+\left(a_{0}+b K_{P}\right) s+b K_{I}}
$$


To determine the parameter of $P I D$, one of the way to find its parameter was trial and error in complex plane using root-locus method [5]. For certain pole and zeros of PID, it's found the root locus as shown in Figure 3.

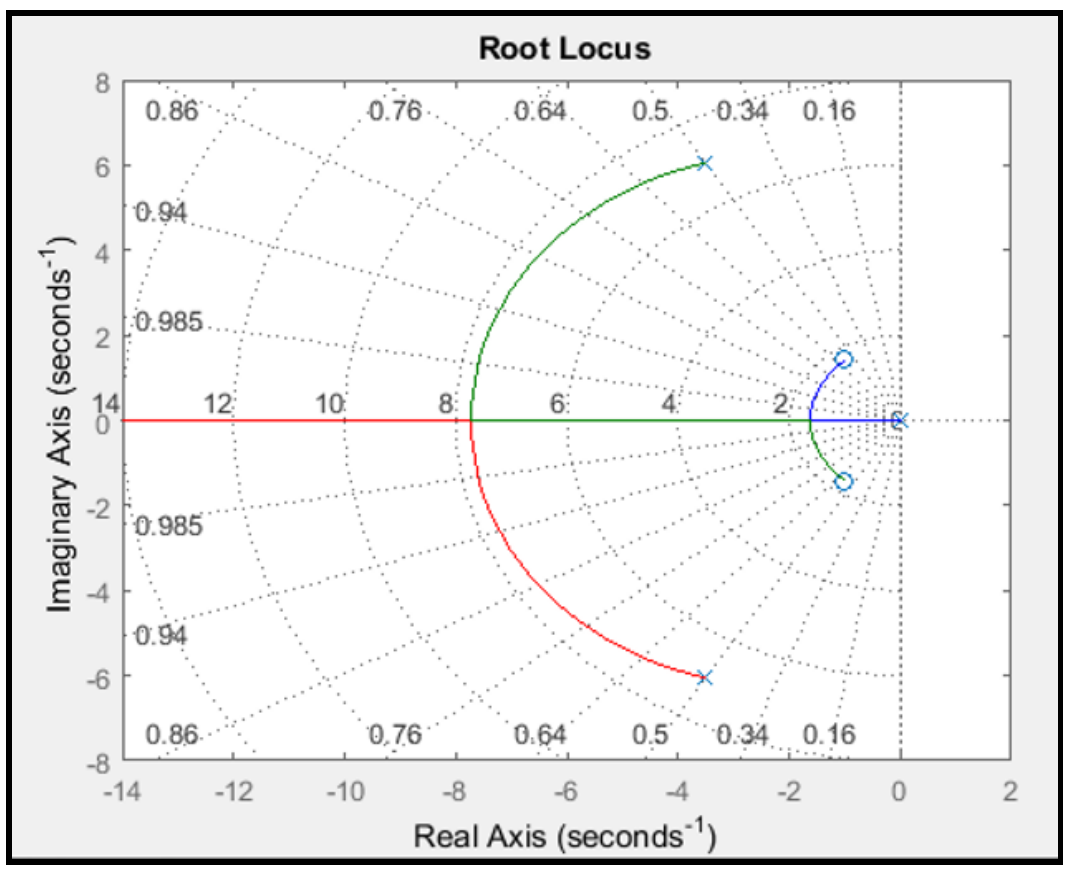

Fig. 3. The root-locus of $P I D$ on optimal of inverted pendulum.

The response of optimal plant using PID control was found as shown in Figure 4.

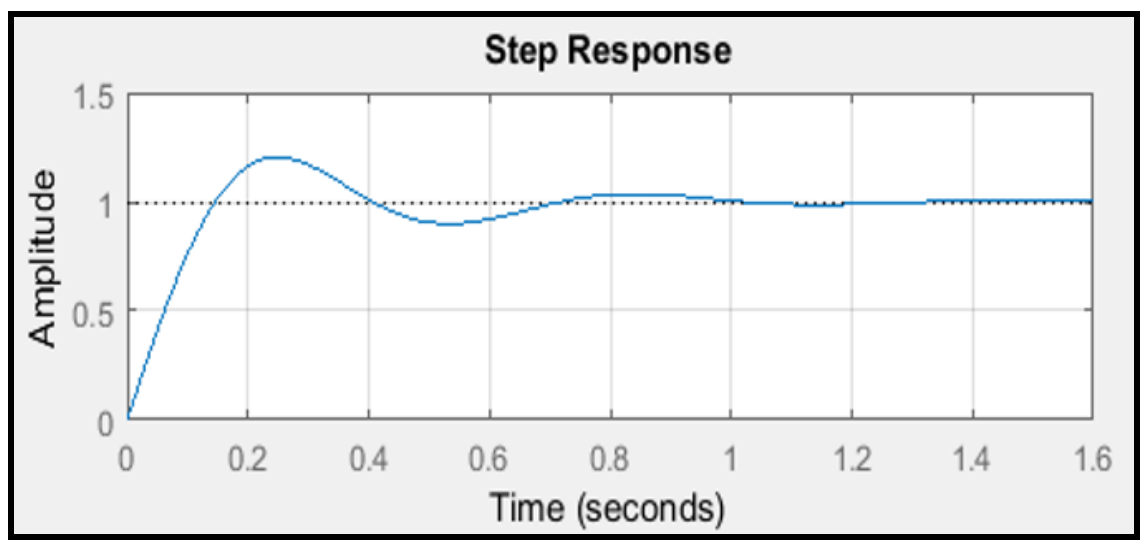

Fig. 4. The response of PID control on optimal of inverted pendulum.

\section{The simulation method of design using simulink}

The response of the plant using feedback and PID have been shown using the MATLAB's program as depicted on Figure 2, Figure 3 and Figure 4. The response of the system should be simulated by using SIMULINK [8-10], to shows various changes in parameter selection on $P I D$, as shown in Figure 5. 


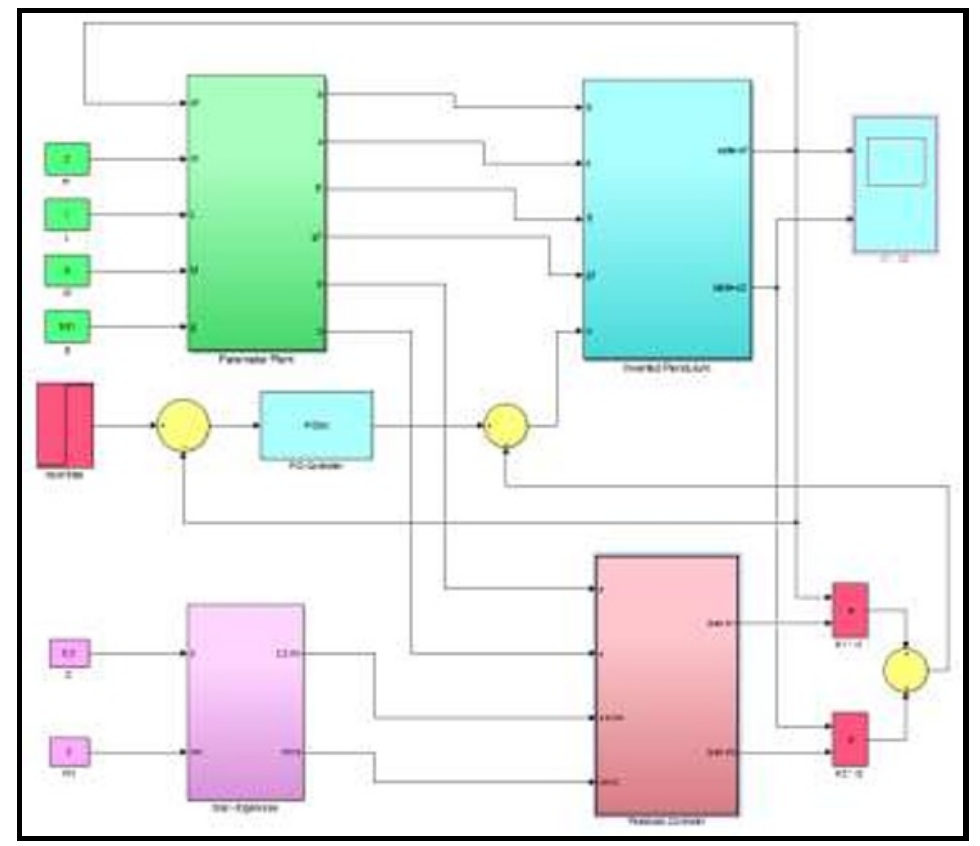

Fig. 5. Simulation using SIMULINK.

According to Equation (3), the sub-system parameter and plant from Figure 5 have structure of parameters as shown in Figure 6 to Figure 10.

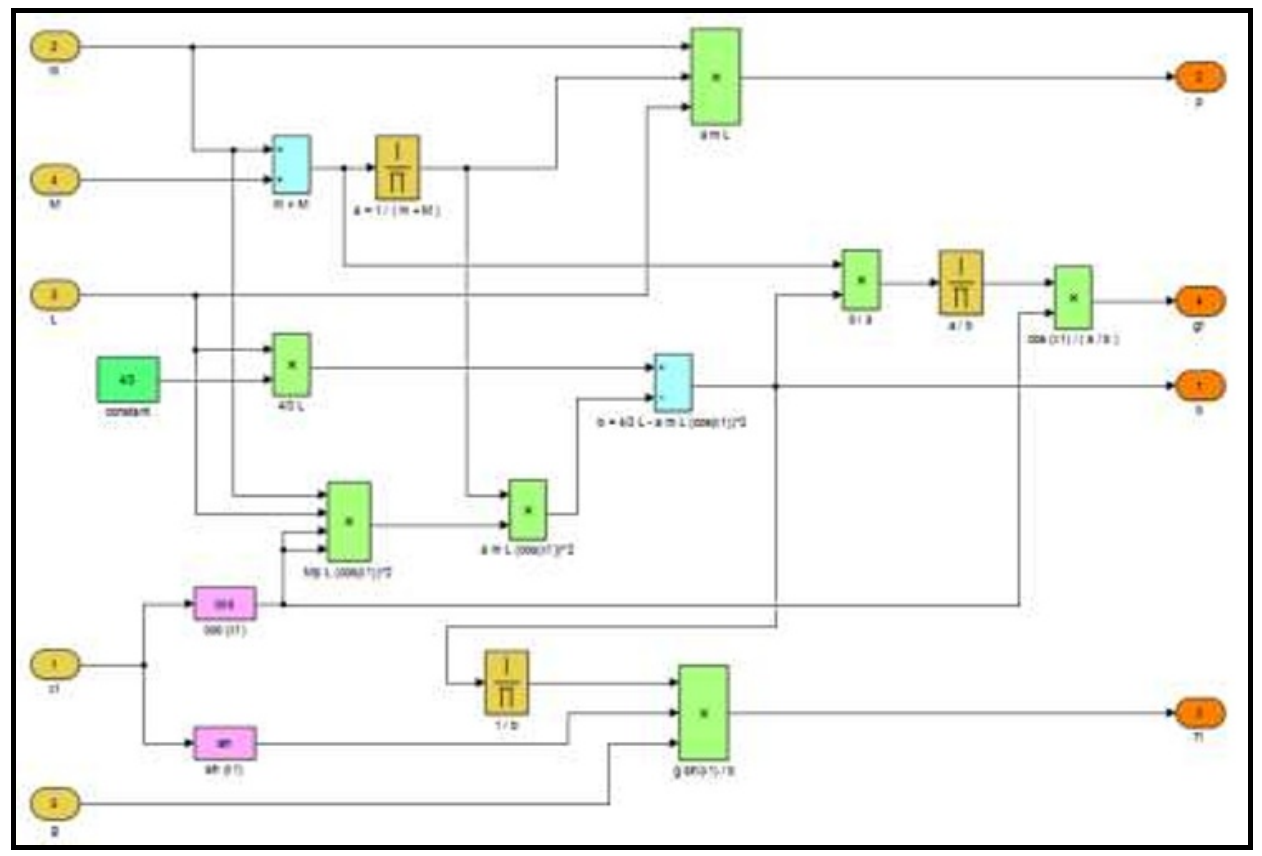

Fig. 6. Sub-system parameters. 


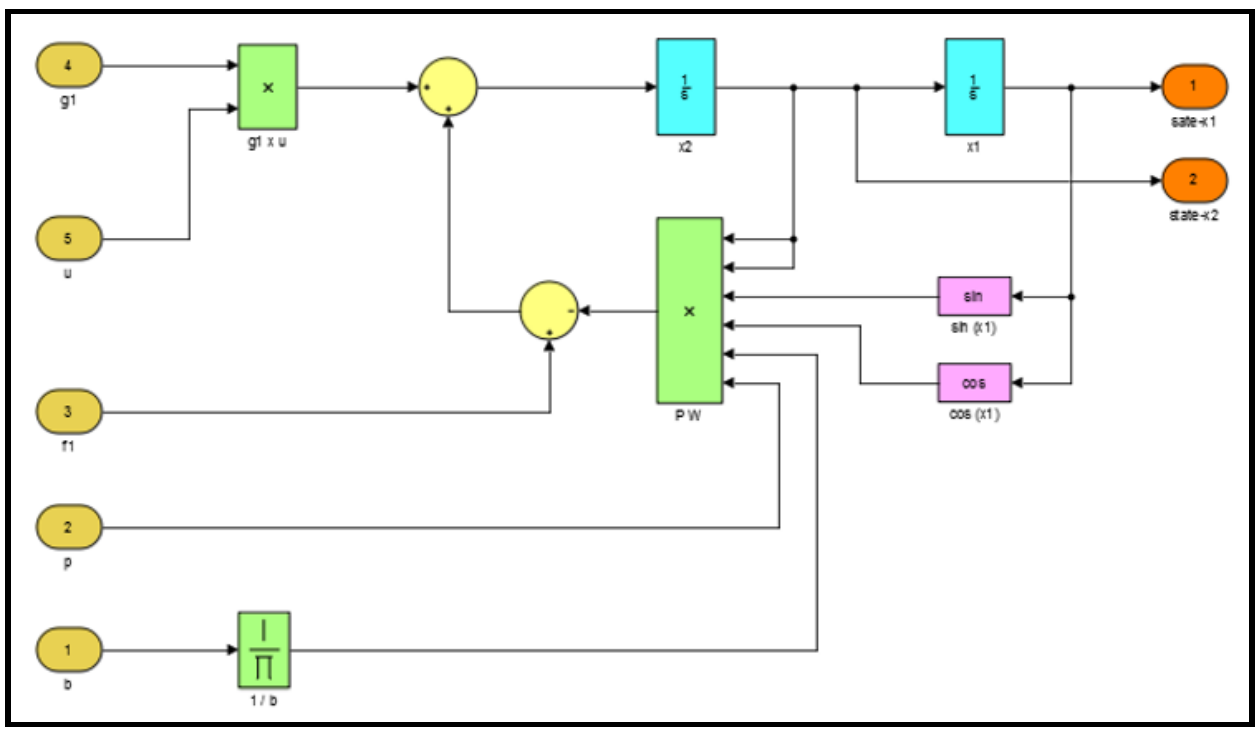

Fig. 7. Sub-system of plant.

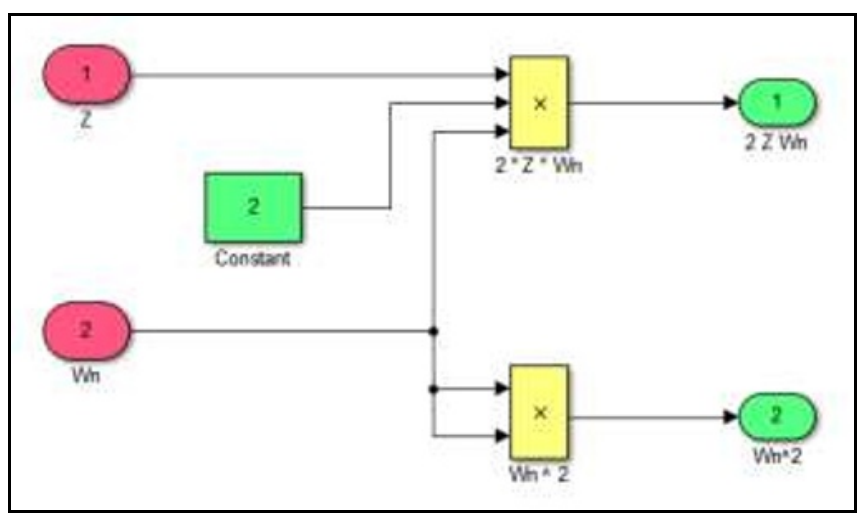

Fig. 8. Sub-system of input.

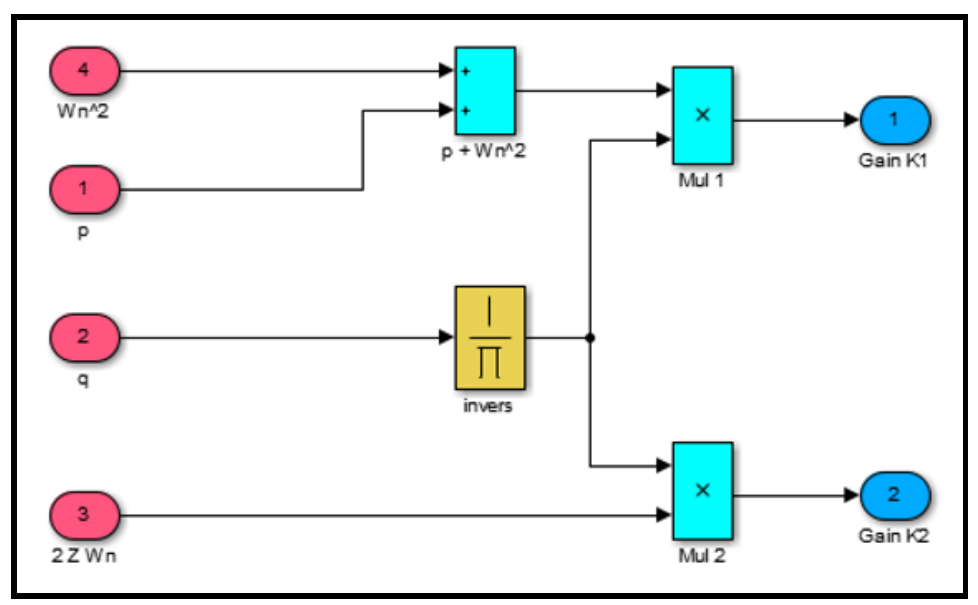

Fig. 9. Sub-system of feedback controller. 


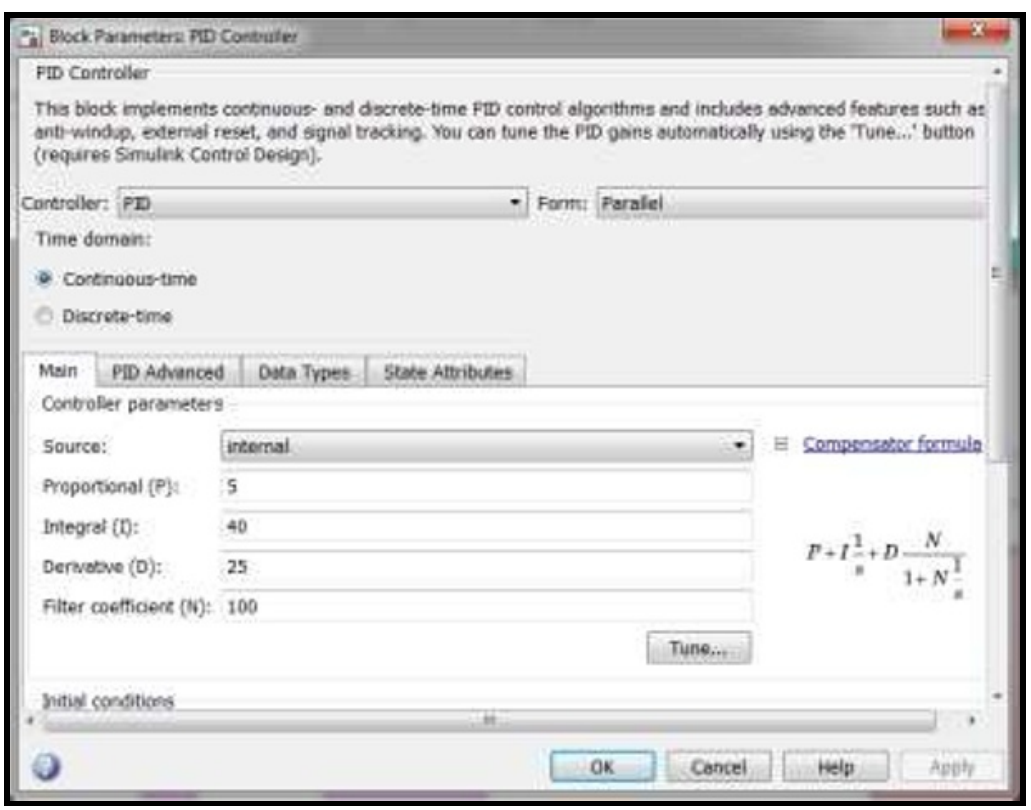

Fig. 10. Sub-system of PID controller.

All blocks in the sub system are arranged according to the formula in the Equation (1) and Equation (4). Subsystem Figure 9 was made to implement an optimal control system, so that at any time the system performance can be regulated through certain damping factors and certain natural frequencies. While the PID control parameter settings are only given through Figure 10. Giving these parameters is given after an analysis of the placement of the pole through the root locus.

\section{The simulation result}

The simulation response according to Equation (1) in the form of open-loop system by using SIMULINK is shown in Figure 8. The simulation response according to Figure 7 in the form of closed-loop system is shown in Figure 9.

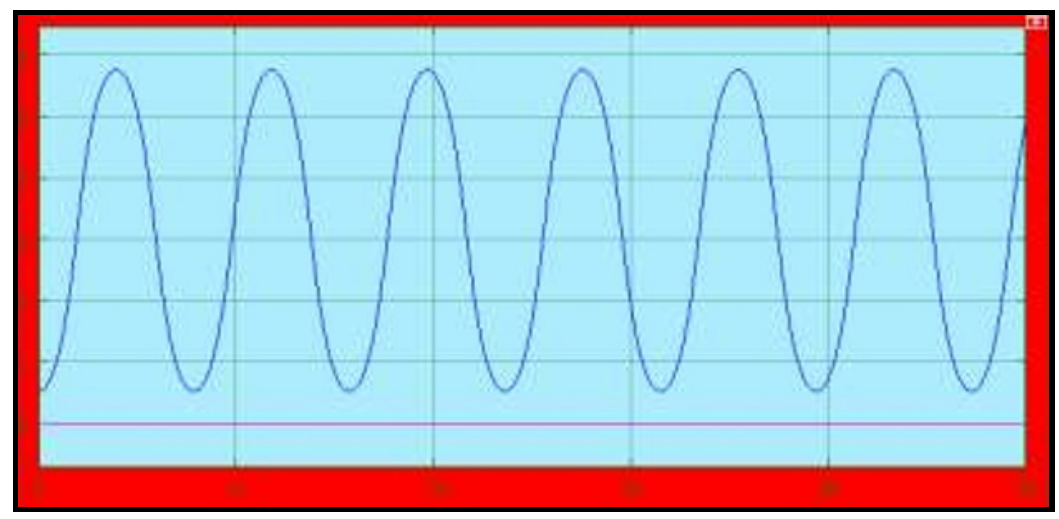

Fig. 11. Responses of open-loop nonlinear inverted pendulum. 


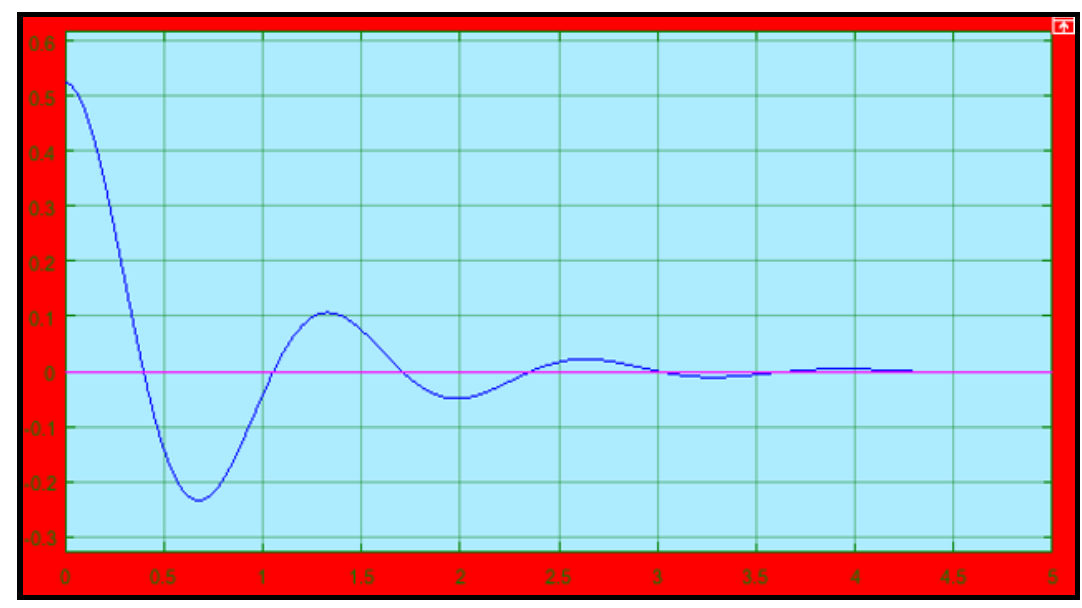

Fig. 12. Responses of closed-loop using only feedback controller.

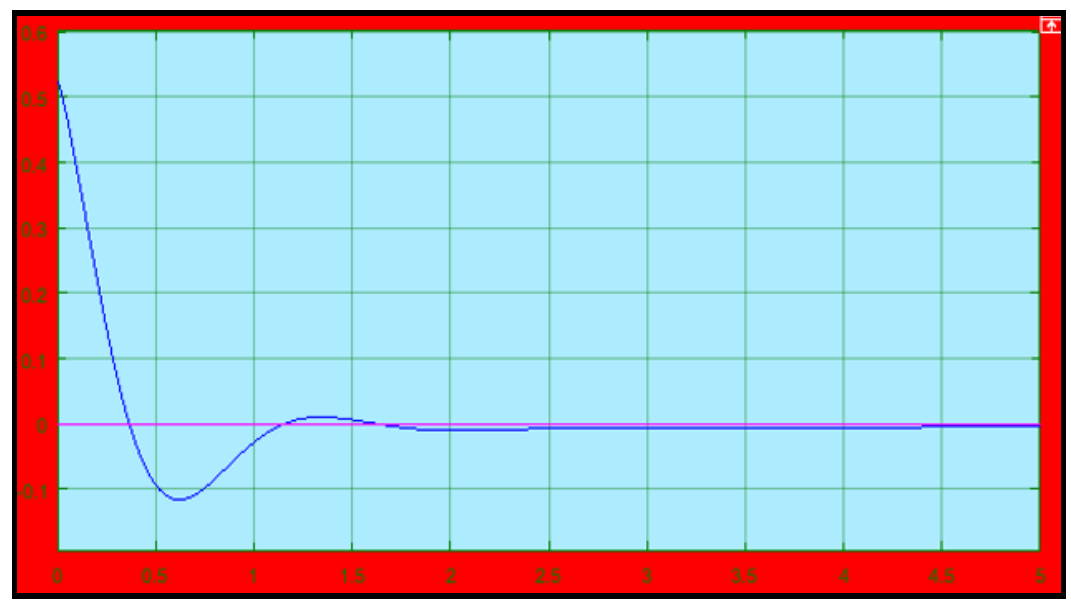

Fig. 13. Responses of closed-loop using pid-feedback controller.

\section{Conclusion}

There are three results were given on Figure 11, Figure 12 and Figure 13. The response of open-loop system always oscillate an unstable. The response on closed loop system only using feedback with proportional control as shown in Figure 12, has stable and response are damped oscillation. By using PID control as shown in Figure 13, plant has stabilized using optimal control. PID was designed using root-locus approach to get the best value of gain parameter at PID controller. The simulation using SIMULINK gave the good result when $P I D$ controller combined with optimal controller. PID controller guarantee the value of error steady-state approaching zero. The response on Figure 9 was stable compare to Figure 8. Performance of the response can be settled in SIMULINK (Figure 5) by using PID and the input on desired characteristic sub-system. 


\section{References}

1. T. Pangaribuan, M.N. Nasruddin, E. Marlianto, M. Sigiro. IJET, 7,2: 823-827(2018). https://www.sciencepubco.com/index.php/ijet/article/view/13217

2. A.M. El-Nagar, M.L. Bardini, N.M. El-Rabaia, Alex. Eng. J., 53,1:23-32(2014). https://www.sciencedirect.com/science/article/pii/S111001681300118X

3. Y. Becerikli, B.K. Celik. Math. Comput. Modell. 46:24-37(2007). https://www.sciencedirect.com/science/article/pii/S0895717707000076

4. D. Kaplan, L. Glass, Understanding nonlinear dynamics. New York: Springer (1995). p. 209-240. https://www.springer.com/gp/book/9780387944234

5. K. Ogata, Modern control engineering, Boston: Prentice-Hall (2010). p. 63-72, 183211, 722-735.

http://sharif.edu/ salarieh/Downloads/Modern\%20Control\%20Engineering\%205th\%20 Edition.pdf

6. T. Pangaribuan, M.N. Nasruddin, E. Marlianto, M. Sigiro, IOP Conf. Ser.: Mater. Sci. Eng. 237,012005:1-6(2017). https://iopscience.iop.org/article/10.1088/1757-899X/237/1/012005

7. S.P. Siahaan, T. Pangaribuan. IOP Conf. Ser.: Mater. Sci. Eng. 237,012029:1-6(2017). https://iopscience.iop.org/article/10.1088/1757-899X/237/1/012029

8. Morgado, V.J. Rivas, R. del Rio, R. Castro-Lopez, F.V. Fernandez, J.M. de la Rosa. Integration, 41,2:269-280(2008).

https://www.sciencedirect.com/science/article/abs/pii/S0167926007000454

9. Y. Zhan, J.A. Clark. Journal of System and Software, 81,2:262-285(2008). https://www.sciencedirect.com/science/article/abs/pii/S016412120700129X

10. P. Chanjun, G. Yingqing, Chinese Journal of Aeronautics, 26,2:319-325(2013). https://www.sciencedirect.com/science/article/pii/S1000936113000204 